\title{
Diasporic films and the migrant experience in New Zealand: A case study in social imagination
}

\section{Arezou Zalipour}

University of Waikato, New Zealand

\section{Adrian Athique}

University of Waikato, New Zealand

\begin{abstract}
Drawing upon interviews and focus groups with Asian migrants, this article interrogates responses to 'diasporic' films that seek to represent multicultural experiences in contemporary $\mathrm{New}$ Zealand. We argue that these responses provide an effective demonstration of the operation of the 'social imagination', a discursive process that articulates the fundamental linkage between symbolic representation, community formation and social action. As our respondents narrated the personal meanings that they construct around ethnically specific media, they were compelled to describe known and hypothetical others, to elucidate symbolic and moral codes, and to reveal social empathies and anxieties. In this study, we found that discussions around migrant stories revealed a series of deeply personalised notions of self and place that were always situated in juxtaposition with externalised projections of community formation and the 'mainstream' culture. This dynamic reflects what can be conceptualised as the central preoccupations of a 'diasporic social imagination'. These responses, therefore, constitute a case study of social imagination at work in a multicultural context, underlining the utility of narrative media in providing a public forum for discussing cultural diversity.
\end{abstract}

\section{Keywords}

Asian diaspora, diasporic audiences, New Zealand film, social imagination

\section{Corresponding author:}

Arezou Zalipour, School of Arts, University of Waikato, Private Bag 3105, Hamilton, 3240, New Zealand. Email: arezouzalipour@gmail.com 
New Zealand is officially described, and effectively operated, as a bicultural nation guided by the Treaty of Waitangi. Nonetheless, this society of 4.5 million people also appears markedly multicultural and multi-ethnic at the beginning of the 21 st century. European migrants and their descendants, referred to as Pakeha, constitute a broadening range of European cultures that go well beyond a singular British heritage. The Maori peoples of New Zealand are also now hosts to a large number of recent arrivals from across the Pacific region, giving Auckland the largest Pacific Islander population of any city in the world. Further, almost a quarter of Auckland's population is now classified as 'Asian', this itself being a catch-all term for a wide range of peoples and cultures covering half of the human species. As such, in considering the ethnic demography of contemporary New Zealand, many scholars believe that New Zealand's increasing cultural diversity is a reality that simply cannot be ignored any more (Smeith and Dunstan, 2004; Ward and Masgoret, 2008). Despite their growing physical and statistical visibility, however, it remains difficult for members of the Asian diasporas to create a significant presence in the vibrant sphere of cultural production fostered by a range of official agencies in New Zealand.

The relative absence of a substantive Asian New Zealand presence on-screen reflects not only the export orientation of commercial media productions towards the Anglophone world, including a close relationship with nearby Australia, but also the primacy of an official ideology that frames biculturalism as a set of ongoing negotiations between European and Maori peoples. Nonetheless, there have been healthy signs in recent years, of media productions being made by Asian New Zealanders that attempt to represent a wider range of social and cultural experiences among the contemporary population. Although their exposure within the media mainstream has been limited, these diasporic media productions are critically important, not least because the communicative sphere of media remains vital for effective public participation in contemporary life and society. In that light, we can argue that the role of media in increasing the visibility of Asians in New Zealand society, and their discursive incorporation in the national community, becomes crucial at a time when multiculturalism is evolving within the country.

\section{Hybridity and difference in media consumption}

Multiculturalism can be seen as an internal reorganisation of the national narrative in order to accommodate greater social, but primarily ethnic, diversity. Alternatively, it can be seen as part of a worldwide mosaic of human mobility fostered through migrations, mass communications and the wider field of globalisation. At either scale (or, indeed, simultaneously at both) the operation of media made and/or consumed within a migratory experience of displacement, pluralism and reorientation readily brings into question the post-Second World War wisdom that mass media have primarily national aesthetics that correspond with stable, and relatively homogeneous, national audiences (see Higson, 2000; Schlesinger, 2000). Increasingly, the worldwide dispersal of media artefacts operates in parallel with the dispersal of human beings, and the steady growth of ethno-cultural diasporas (Karim, 2003). In his influential analysis of the cultural dimensions of globalisation during the 1990s, Arjun Appadurai (1996) claimed that the new possibilities for worldwide - and enduring - consumption by migrants of media 
artefacts addressing their own ethnic specificity heralded the formation of 'diasporic public spheres'. These putative social bodies are described as mobile post-national communities linked internationally through ethnic identification and electronic media (Appadurai, 1996: 22).

In Appadurai's reading, geographically stable national publics were likely to be subsumed by ethnic cultures flowing back and forth across the surface of the world, and maintained over the longer term by ethnically specific channels of communication. However, an influential earlier account of cultural identity among migrant communities by Stuart Hall argued powerfully for the inherent hybridity, reinvention and appropriation of the identities forged through the dislocated cultural practices of the migrant experience (Hall, 1990, 1993; Hall et al., 1996). Here, the maintenance by migrants of ethno-cultural connections with 'homeland' cultures is necessarily unstable, since cultural practices and identities are constantly reshaped by complex sets of proximate and long-distance social relations that involve both the new home and the old. Understood this way, diasporic cultures are not mechanisms for cultural maintenance and fixity, but are instead processes of becoming that combine strong personal experiences of both the universal and the particular in human societies.

Although debates about boundary maintenance and cultural fusion continue, the consolidation of the idea of a 'diasporic subject' in the humanities has logically given rise to the paradigm of 'diasporic audiences', denoting global constituencies for ethnically specific media (see Athique, 2011). In attempting to provide a suitable theoretical model for the diasporic audience, Stuart Cunningham, extrapolating from the work of both Appadurai and of Todd Gitlin (1998), has described diasporic audiences as inhabiting narrowcast media environments which are 'public sphericules'. That is, they are 'ethnospecific global mediatised communities' which 'display in microcosm elements we would expect to find in the public sphere' (Cunningham, 2001: 134). From the perspective of their host nations, however, they are 'social fragments that do not have critical mass' (Cunningham, 2001: 134). If we follow Hall's lead, however, we are encouraged to consider the overall mix of cultures represented in the media consumed within the community, and look for evidence of 'crossover' between the cultures, either in the texts themselves or in the exposition of programming choices by audience members (see Khorana, 2013). If we characterise the two available models in broad terms, then a diasporic media audience can either be considered to be engaged primarily with the transnational maintenance of a global ethnic culture, or beset by the challenges of combining different cultural streams within the national space. In either case, the cultural practices of diasporic communities are commonly seen as 'a struggle for survival, identity and assertion' (Cunningham, 2001: 136).

\section{Unlocking the social imagination}

It is worth reflecting upon the extent to which engagement with media cultures has come to be positioned as a matter of survival in contemporary societies. That is, we have to ask why the stakes are set so high in the entertainment rituals of everyday life? In a large part, the answer lies in the massive investment in national media systems as socialising forces in the second half of the 20th century. With the coming of satellite television, playback 
formats and the worldwide web, this long-term investment in common media cultures has been forced to accommodate the rise of narrowcast media and niche audiences across the media spectrum and likewise across the social spectrum. At the same time, the steady relocation of non-European migrants into the developed nations has further highlighted the increasing diversity of national populations and the mobility of cultural forms, aided by a raft of new technologies. A further factor to consider is the predominance of a new understanding of cultural practices in everyday life as major sites of identity formation with political significance, as reflected by the 1960s notion that the 'personal is political' and by the rise of critical disciplines such as cultural studies. All of these have contributed to the impetus for a wide range of studies that focus upon the media usage of migrant populations, and the resulting configurations of social identity and their implications for managing diversity and assessing processes of assimilation or alienation (Gillespie, 1995; Cunningham and Sinclair, 2000).

The theoretical notion that has been most central to discussions of media reception for the past 30 years has been Benedict Anderson's (1991) concept of the imagined community. Anderson:

famously posited the effects of media use upon the imagination as a transformative force in the socialisation of a modern community ... [where] participation in the new mass audiences facilitated by the emergence of print media encouraged individuals to imagine themselves as part of larger and more abstracted social formations. (Athique, 2008: 26)

For textual researchers, it is this notion of a collective symbolic imagination that has allowed for the reading of cultural artefacts as allegorical renditions of identifiable societies or social groups. For audience researchers, those articulations are commonly aligned with an a priori social group whose collective subjectivity can be read off a sample of responses to media content. The notion that the social is imagined into being through performance has also been amenable to studies of media effect, since media consumers are considered susceptible to nation-building messages encoded into media artefacts (Athique, 2008: 26). The influence of this concept is referenced explicitly in Appadurai's account of diasporic publics:

The world we live in today is characterised by a new role for the imagination in social life. To grasp this new role, we need to bring together the old idea of images, especially mechanically produced images (in the Frankfurt School sense); the idea of the imagined community (in Anderson's sense); and the French idea of the imaginary (imaginaire) as a constructed landscape of collective aspirations, which is no more and no less real than the collective representations of Emile Durkheim, now mediated through the complex prism of modern media. The image, the imagined, the imaginary - these are all terms that direct us to something critical and new in global cultural processes: the imagination as a social practice [...] The imagination is now central to all forms of agency, is itself a social fact, and is the key component of the new global order. (Appadurai, 1996: 31)

Although Anderson's original explanation can be called technologically deterministic, it is much less so if we focus on the communicative content of the media rather than simply the existence of its infrastructure. Media technologies themselves may indicate the 
potential, and even the inevitability, of modern community formation, but they cannot of themselves explain the nature of such communities. If an assumed connection between media consumption and communal identity is to be accepted, we should seek to better understand the nature of the imaginings which make such relations possible. On that basis, it seems quite perplexing that most of the subsequent research on 'imagined communities' has focused more or less exclusively on the latter part of that couplet (that is, on community). Arguably, what we should pay equal attention to is what this emphasis on imagination implies in the practical context of social research. Rather than a provocative equation of imagined affinities with the positivist doctrines of Durkheim, it is more immediately productive in this regard to turn to C. Wright Mills' (1959) pioneering conceptualisation of sociological imagination. According to Mills, the social imagination is the set of cognitive processes where two abstract concepts of social reality - the individual and society - are linked. Mills therefore defined sociological imagination as 'the capacity to range from the most impersonal and remote transformations to the intimate features of the human self - and to see the relationship between the two' (Mills, 1959: 8).

It is this capacity to interlace our position within society that allows us to identify and understand the relationship between wider social forces and our personal actions. In doing so, social imagination makes the lives of individuals both functionally plausible and meaningful, reminding us that identity is as much an external matter as an internal one. According to Mills, the concept of social imagination enables us 'to take into account how individuals, in the welter of their daily experience, often become falsely conscious of their social positions' (Mills, 1959: 5). For our present purposes, we will put aside the Marxist notion of a 'false' consciousness, because that obviously requires the imposition of an external judgement upon the social imagination of others. What we want to emphasise instead is the foundational premise - that imagination is not simply a device for the narration of abstract symbolic relations. Far from being narcissistic fantasy, the everyday operation of social imagination is fundamental for connecting humanity with the material world, providing the necessary terrain for collaboration in social behaviours. As such, an analysis of these imaginative processes as primary data is warranted, since they can be spoken and thereby offer us an opportunity to look at the way social imagination has shaped particular individuals, the ways in which they perceive the world around them, and how they seek to assess, influence and interact with it.

The application of the concept of social imagination in sociology is often inflected by the power relations between the research expert and the research subject. That is, a welldeveloped 'sociological imagination' can be associated more narrowly with the particular role of the sociologist, which 'requires us ... to "think ourselves away" from the familiar routines of our daily lives' (Giddens, 2013: 5). Arguably, the real value of the concept is precisely the opposite, since the articulation of their own social imagination by research subjects takes us deep into their social experience and consequently reveals much about the embedding of symbolic and abstract relationships, both near and far, within the fabric of their everyday lives. Because the articulation of social imagination through language is a relativistic process, a measure of empathy becomes requisite for anticipating relationships and the consequences of social action. This, then, would appear to be the point at which imagination conjoins with community. Thus, when people say what they think about media narratives, they inevitably deploy a wider social 
imagination that situates them in relation to the narrative, protagonists and the wider social context of their lives. Without a doubt, in contemporary societies, ethnic or political affiliations are powerful symbolic orders that shape the operation and articulation of this process. Nonetheless, we would argue that the function of social imagination is a much larger, but also more intensely personal, process that is worthy of consideration in its own right.

\section{Theory in action}

In order to demonstrate how a focus on social imagination has practical utility for audience research in media studies, we must return to the specific context of New Zealand and the empirical foundations of our enquiry. We employ the concept of social imagination here for the purposes of understanding audiences within a particular diasporic context. In presenting a range of commentary from respondents collected in relation to films that take migrant experiences as their central subject matter, we are naturally concerned with the relationship between the diasporic audience and the diasporic film. However, we also seek to emphasise that audience responses are not arbitrated solely by the positioning they adopt with respect to the diegesis of the film itself, but also by a wide variety of external referents that further situate their perception of themselves, society and the world. This is in keeping with our basic premise that audiences' responses to media text are expressions of their social imaginations and are influenced by their socially, culturally, politically, ideologically and geographically located selves. In the case of diasporic audiences specifically, it became clear to us that the interpretive resources and competences of respondents were characterised by a tendency to identify with various aspects of the diasporic text in a distinctive fashion. That is, their sense-makings, textual interpretations and social commentaries are necessarily affected by their diasporic (and selfconscious) sense of being 'here' and not 'there'.

Since the richness of reception studies rests in a large part upon the content provided for stimulus, some brief notes on the film content used in this project seem beneficial here. The selected films included My Wedding and Other Secrets (2011, co-written and directed by Roseanne Liang); Apron Strings (2008, co-written by Shuchi Kothari and Diane Taylor and directed by Sima Urale) and Desert (2010, written and directed by Stephen Kang). Asian diasporic film is a nascent phenomenon in New Zealand, and it is only comparatively recently that members of Asian diasporas have started to get involved in making films about their experience and life in the country (Zalipour, 2013). As one might expect, the manner of production, distribution and public reception of Asian New Zealand film varies. Apron Strings and My Wedding and Other Secrets emerged from an industrial mode of film production (particularly in the case of the latter, which had a significant budget and an established film company behind it). Conversely, Desert is a low-budget digital video production, attaining a low level of distribution and audience compared with the other two films.

My Wedding and Other Secrets is a textbook story of intercultural negotiation, where a Chinese New Zealand girl (Emily Chu) has to decide between love for her Chinese parents and her love for a Kiwi boy (James Harrison). The film clearly emphasises the generational conflicts that can arise around maintaining the traditions and customs of the 
migrants' original culture alongside those of the new country. Centred instead upon New Zealand's Indian community, the film Apron Strings develops similar avenues of contemplation. The film presents parallel accounts of an Indian family alongside a 'Kiwi' family, exploring the various ways in which each member finds the courage to unleash the past. Anita, the star of an Indian TV cooking show, has settled in New Zealand with her son Michael. Michael decides to explore his 'Indianness' with the aid of his mother's sister, Aunt Tara. Tara runs a Curry House in South Auckland. In the same neighbourhood, Lorna, a Pakeha (European) New Zealander runs an old-fashioned cake shop and lives with her old mother and wastrel son, Barry (who prefers Tara's cooking to the meals made by his mother). The characters of Apron Strings clearly struggle to forge stable relationships within the diasporic and multicultural milieu. By contrast, the Korean New Zealand film Desert is rather different, in that it primarily focuses on the affective and material predicaments of Korean migrants in New Zealand. The narrative centres on Jenny, a young Korean girl, and her attempts to achieve a stable and integrated life after being abandoned by her Kiwi boyfriend.

In carrying out the reception studies, participants were recruited via convenience sampling from the three largest Asian diasporic communities in New Zealand at the time this research was conducted (Chinese, Indian and Korean migrants). Respondents were invited to watch the film whose diegesis centred upon the experiences of their own ethnic community. Each respondent was provided with a copy of the selected film (in DVD format) and asked to watch it prior to participating in a series of focus groups and interviews (held within two or three days of their viewing). The participants who volunteered to take part were relatively homogeneous in terms of age, level of education and professional status, and consisted of adults primarily from the first generation of diaspora. There was no gender weighting of the sample and the resulting gender composition has a female bias (13 male and 21 female). The research was conducted by the lead author, who has a diasporic background but is not a member of any of the ethnic communities with which this research enegaged. The lines of questioning explored in the interviews and focus groups were directed towards the elaboration of issues foregrounded in these (New Zealand's most recent) 'diasporic' films (see Zalipour, forthcoming).

\section{Positioning the self}

The expression of social imagination is a matter of position-taking, and consequently the starting point for the majority of respondents was the narrative positioning of the self, articulated through the trajectory of their own travels and life stories, and their significance as a framing of identity. Our 'loaded' sample of 'diasporic films' naturally prompted respondents to consider these narratives in relation to their own present situation as Asian migrants to New Zealand. Accordingly, the responses provided by participants indicated a high degree of personal identification with narratives and themes, typically expressed through a strong relation to their own lives and memories. Sometimes this was intended to express affinity for the experiences of protagonists in the text, and at other times the comparison was deployed in order to express a differentiation from their own experience. For many of our participants, the social construction of a mixed (or 'hyphenated') identity was evident in their self-presentation. For example, a male participant from an 
Indian background talked about the conflictive complexities of a hyphenated identity, implicating friends who also shared the same feeling:

Because growing up in New Zealand, the people here, Kiwis, they view you as an Indian coming from India. So they assume that you behave just like one of them, and the Indians, they think that you don't quite fit the Indian bracket. You're more like a Kiwi. People like us actually don't fit in a neat box and that identity is neither here nor there. From that time I arrived in New Zealand till now that still hasn't changed.

Self-understanding was often constructed through the prism of generational distinctions within migrant communities. In order to position their own self and identity, the participants across the three case studies frequently referred to their children and parents, highlighting the ways that different diasporic generations inhabit the social and cultural dynamics of the new home. One discussant from Indian origin (whose parents migrated to the Middle East and then came to New Zealand to settle) reminisced about them to describe herself:

[...] compare me with my mother and where I stand as a migrant, so my mother was very loyal to her Indianness but also wanted to deny her Indianness sort of like, she wanted to drive a car, she wanted to travel, she wanted to do this and that. She was also going to watch Bollywood films and take part in activities of the Indian community there. For her it was like 'I don't want to be that Indian. I want to be little bit western to show that I'm not Indian.' [...] As I grew up, there was a focus on being Indian, all that sort of stuff. As I grew up I wanted to have my own identity. [...] My mother in a sense rejected that [the Indianness]; my generation went back and looked for it and found it again, that is my language and culture. So I couldn't choose the language and culture I want my daughter to learn, now she is starting to see where she stands and wants to know as the third-generation migrant.

A female Korean participant said she migrated to New Zealand in 1998, but believes that, unlike her own children, she has not become a 'Korean-New Zealander': 'I'd like to call myself Korean [and] my kids would be "Korean New Zealanders", [...] I came here when I was 35 years old [and] people like me - we try to keep our origin.' This personalised hybridity is seen as being common among diasporic individuals (Hall, 1993). With their key generational distinctions, these comments demonstrate something of the complexity and trajectory of a partial assimilation. Ethnicity was, naturally enough, a major marker of selfhood but, at the same time, it was not the only point of reference. Responding to the film, My Wedding and Other Secrets, a Chinese female participant emphasised her positioning primarily as a mother, extrapolating the narrative to the future of her 'little girl' and the differing consequences 'if she falls in love with a Kiwi boy or a Chinese boy'. An Indian respondent also spoke of the dilemmas of motherhood, where her own escape from traditional expectations in India through a second partnership with a Kiwi was counterposed by a strong desire for her own children to marry suitable partners from 'back home'. Thus, for migrant parents across the different sample groups, there were mutual concerns over generational conflicts and the maintenance of their 'original' culture and traditions by their offspring. 
More broadly, the participants across the three case studies articulated the 'split' dynamics of a 'diasporic self'. This positioning appeared to be fluidly constructed in resonance with many external factors in the new environment, always in relation to imagined others, and structured by the cleavage between two ideal types: the ethnic/ diasporic and the majority/mainstream. It is notable in this particular context that the positioning of the 'majority' by participants was not structured by any clear distinction between Maori and Pakeha. Ethnic positioning could also be highly strategic. One respondent observed that some migrants 'capitalise' on their ethnic identity, while the groups as a whole tended to think of themselves as people 'who have not capitalised on' their Indianness, Chineseness, etc. Beyond the comparison of their own identity to the circumstances of the films' protagonists, our respondents would inevitably refer their own experiences to a broader scale of social reality that reflected contemporary New Zealand as a whole. In this sense, we found that the responses of participants provided useful evidence of the capacity to extrapolate individual circumstances to issues at the societal level. This aligns strongly with Mills' (1959: 3-24) original exposition of the sociological imagination at work.

\section{The personalisation of place}

The positioning of self and identity by migrants inevitably produces a strongly comparative sense of here and there. The awareness and experience of living across multiple locations clearly stimulates a need to conceptually relate self to a necessarily complex sense of place. This was true for first-generation migrants born in one country and relocated to New Zealand. It was also true for members of the second generation, who remained culturally associated with one ethnic culture but were reared and educated in New Zealand's particular ethnic and cultural framework. As such, the place of origin, though temporally and spatially at a distance, remains linked to migrants and their subsequent generations (Anthias, 1998; Baumann, 2000; Clifford, 1994). Naficy (2001) has noted the intense desire to return to the homeland in exilic films, arguing that in diaspora, home must be imagined, in order that it may be longed for, desired, returned to physically or ideologically re-produced within migrant communities. In our case studies, the sentimental memorialisation of homeland did not appear to be prevalent in the responses of the participants. Instead, responses tended to revolve around preoccupations with the ways a sense of belonging can be performed in various aspects of diasporic life. For example, in response to the film Apron Strings, an Indian female discussant reminisced about the time she migrated to New Zealand more than a decade previously. For her, migration was to free herself from the arranged marriage that was imposed on her by her family and community and she stated clearly that she would never think of return. This respondent's characterisation of the two societies, albeit somewhat contradictory at different points of the narrative, was dominated by an explicitly comparative sense of here and there. For example:

Things are out of control here in New Zealand. Back home [in India] things are in control. For example, my son was 17 and New Zealand law says he can move out and stay on his own and get a partner. If it was back home, then no way he could move out and be on his own; he had to 
get married to someone that family has agreed. [...] Society back home won't let you do that. Society defines these things. In this society rules and regulations are totally different. Here if my son leaves what I can do? In India the boy himself will not say it or do it because of the respect, because of the community, because of the shame.

Many participants referred to some aspects of original homeland culture that can be reconstructed or abandoned totally in New Zealand, stressing the ways the new place can offer diasporic subjects an opportunity to do so. Commenting upon the film itself, the same respondent noted that:

You can't be the same person because you're breaking that shell - something Tara didn't even do [though she was in New Zealand]; even if you were in India, the same thing would apply. It's only that here you have more space of doing such a thing.

One Chinese discussant highlighted: 'I care about New Zealand because people here treat me so well and they are such kind and nice people as compared to many people in my city back in China.' The participants' candid comparisons of home countries with New Zealand indicated that everyday social relations were an important factor in defining the relative merits of relocation. Accordingly, the ethnic and cultural references to place were always qualified and complex, and therefore tended to undermine any simplistic notions of home as a nostalgic constant. Critical comparisons and trade-offs between cultural norms appeared to arise naturally, despite the backdrop of 'multiculturalism' which gives definitive weight to ethnicity in matters of self and identity.

In a majority of cases, the sense of place was constructed around the theme of 'here is better' as manifested in participants' position-taking on their New Zealand-based lives. These personal experiences naturally 'scaled up' to perceptions of national cultures as places of well-being. Reflecting this 'forward' gaze, the participants in our study articulated the notion of home primarily as a place that is left behind and not actively desired. This 'remembered' home appeared to be confined to familial relationships, as well as being the source of the components of their collective culture that remained central to the expression of their ethnic identities. These practices clearly had symbolic significance in their lived experience in New Zealand, but their memories of home as such were not factual or empirical recollections of place. These imagined geographies were deeply personalised and, in that sense, place was more a temporal than geographic reference. At the same time, the constant coexistence of New Zealand and 'back home' in their life stories encouraged broad comparisons that subsequently shaped their views of cultural and political geography. In that sense, their social imagination provides a vital process for linking the personal and global frameworks that determine the migrant experience.

\section{Community formations}

The axiom of community inevitably entails the juxtaposition of inclusion and exclusion in a new society, and this implicates various other concepts and issues built upon a close linkage between personal identity, political citizenship and communal culture(s). 
In this respect, the participants' responses to these films displayed a general consensus on the central importance of diasporic communities to the migrant experience. Our participants talked about the invisible rules, boundaries, restrictions and sets of values that operate within a diasporic community. In functional terms, these diasporic communities are typically formed in settings where migrants congregated for religious and cultural activities. As such, a process of diasporic socialisation consequently takes place through the slightly artificial enactment of group-specific values and practices. In responding to the film, Desert, a Korean woman discussed the difficulties that can arise within such communities when boundaries are breached:

It's a small Korean community in Auckland and through word of mouth people get to know her [Jenny in the film Desert]. It'll be quite hard to live there in such a small community once Korean people have heard your unfavourable news [her pregnancy].

Similarly, an Indian participant referred to the diasporic community as an 'inside world' with distinct stipulations: 'so getting pregnant out of wedlock is not right according to the inside world' (a comment on the film Apron Strings).

In everyday sociality, the essential need of attachment to some sort of community or collective in the diaspora was cherished by many participants. All Korean discussants expressed their empathies and anxieties about the sense of isolation and exclusion that diasporic subjects encounter in the new country and the role of community attachment as an immediate solution: 'If you come to a new place, you would want to make sure you have friends that you can rely on. When you get involved with activities in church you become part of that community.' Nonetheless, many participants hinted at a strategic balance in the level of attachment to diasporic communities and the dominant community ideology. On occasion, involvement in diasporic community formations was rejected outright. One Chinese participant rejected involvement with diasporic communities in New Zealand and criticised the role of government in this dynamic:

New Zealand government needs to encourage Kiwi activities rather than ethnic and community activities all the time. I never go to Chinese meetings or festivals. Many of these ethnic activities are happening in a large scale in this society. I never go to such community events because I don't like these activities which highlight your ethnicity and make you look different. You are now in this country; if you wanted to be Chinese you should have stayed in China. [...] I don't know why the government creates so many associations for migrants. I understand they are interested in those cultures and want to see how they can contribute to the Kiwi culture. If that is the case it is good, but on the other hand it also enlarges the gap, because you identify these people as being different.

Taking an opposite line, one male Indian migrant saw New Zealand multicultural framework as benefitting his own diasporic community:

I'm connected to Indian community in Hamilton. In New Zealand we don't have those kinds of harassment we hear about in other western countries because of following our own culture, which is great. So the Indian culture is quite strong here but our population is very small. 
Community formation, by its nature, involves inequalities in access and struggles over establishing individuals' rights, the dynamics of participation and the group's broader social presence. Commenting on the role of media representations of diasporic communities in New Zealand, one participant embarked upon a criticism of a migrant parliamentarian's interventional strategies to obtain an MP appointment. This person was described as having utilised multicultural media in New Zealand primarily as a channel for personal visibility, and as having emphasised an attachment to their diasporic community in order to obtain a social and political position within the mainstream culture.

I know [this person] is a Korean who was working on the programme Asian Down Under. She used media to become MP. The Korean community doesn't like her well because she used that position from a media person to become MP; it was easier for her to progress that way. I don't think she's really a right person to represent our community, Korean or even Asians. She says 'I'm Kiwi'. I can understand, but maybe the government, the president thinks that she is representing Asian communities and can pass our message to them, but I don't see she is really working for the community. She participates in multicultural shows but we can't see if she is really approaching in some real way to do something for our migrant societies in New Zealand.

The authenticity of and motives for ethnic representation are closely scrutinised within migrant communities. It is no surprise, then, that the challenges of community orientation are frequently exacerbated and intensified in diasporic contexts. While a few endorsed the importance of a long-term attachment to the diasporic community, it was also apparent that many of participants felt that the need to attach persists only in the early stages of settlement. One Korean female discussant attests to this by saying that: 'The first generation of Korean who came to New Zealand with their children probably with a patriarchal father and domestic mother, they would probably live in the community.' The implication was that diasporic communities are often 'bridgehead' formations, which play a lesser role in everyday life once migrants are settled. The generational dimension is also prominent here. Diasporic community organisations were seen as having less importance by the second generation, who have grown up with their Kiwi peers. Conversely, diasporic communities were seen by migrant parents (from their own point of view) as providing a useful remedial resource, ensuring a measure of cultural transmission to the younger generation alongside their broader socialisation in New Zealand.

\section{Negotiating multiculturalism}

Respondents in all of our sample groups adhered to the view that New Zealand media does not portray 'real New Zealand society' in terms of its ethnic diversity. A lack of genuinely or appropriately representative imagery of Asian migrants in New Zealand media was seen as reflecting a situation whereby:

They think we are still a minority. It is the matter of population number and also influencing the Kiwi society. [...] But still there are not many of us who work with Kiwis so can we say that we are living among Kiwi society? 
When referring to the 'mainstream' of New Zealand society, participants in this study referred to an overarching concept of inclusion/exclusion in several ways. For some (but by no means all) respondents, language was seen a functional element that could hinder integration (to the extent that they endorsed language barrier as 'the biggest problem'). More broadly, however, the issue of 'cultural differences' was raised as a pertinent factor that directly affects opportunities for participation in the mainstream. Inclusion and difference were clearly fraught concepts used to reference a remaining gap between their own cultures and the 'Anglo' culture that is perceived as predominant in the New Zealand context. Despite such difficulties, respondents saw their engagement with the "mainstream' culture as a primary measure of their success in establishing themselves in New Zealand:

So I think because I've grown up here I established myself more as a New Zealander than as a Korean and it's easy for people to assume that I'm Korean and that means I can't speak English and things like that. I sort of try little bit harder to convince them that I'm just a New Zealander.

The importance of enhancing cultural awareness as part of the process of inclusion was highlighted by several participants. A Chinese discussant stresses a 'mutual' process of culturalisation as the pathway to create multiculturalism, noting that there is not 'much education for Kiwis to learn about the migrant groups living in their society'. A lack of understanding of Asian cultures, and of cross-cultural acceptance by Kiwis were frequent reference points in the discussions around the three films. One Chinese discussant explains that 'Some Kiwis have not had the chance to travel and so they have not experienced getting to know another culture and have cross-cultural experience.' Criticism was not merely a one-way affair, however. One female Indian discussant spoke her mind in the focus group by saying that:

It's not that simple; we think they should accept us. We don't accept them either. How often we can accept their culture and say OK. My son brings his girlfriend home and lies down on the couch. This is something I never accept from their culture. We don't accept them as much as they don't accept us.

A successful multiculturalism was therefore also seen as being a responsibility for migrant communities and for individuals. As such, several participants reflected on the ways they (as migrants) can contribute to the Kiwi culture, society and people. One Chinese respondent, for example, stated that 'We should find the ways we can contribute to this culture.' One suggestion for achieving this began from investigating 'what I have in my original culture and how I can apply them to my current practice, life, work and identity in New Zealand'. One common belief held by respondents was that Asian migrants are serving the country in many ways and they should, therefore, be recognised as a major part of New Zealand society. Nonetheless, despite these criticisms, most of the participants held the view that 'New Zealand is moving towards multiculturalism'. For our purposes, what is most striking is that none of the film narratives made any explicit references to the status of multiculturalism in New Zealand, either as a set of policy structures or as a broader national trajectory towards cultural diversity. Rather, these 
were intensely personal stories that foregrounded cross-cultural relationships, adaptation and personal identity. Our respondents were nonetheless compelled to relate these narratives not only to their own personal experiences but also to the 'big picture' of social change. In that respect, diasporic films provided another framework for the level of political debate and self-reflexivity that Mills originally sought to encapsulate in his imaginative positioning of personal circumstances and broader economic conditions.

\section{Conclusion}

The engagement of migrant viewers with films that seek to represent the social dynamics within their own communities is a naturally fruitful site for launching a broader discussion around multiculturalism, diversity and sociability in New Zealand. In that sense, this article serves an empirical purpose by filling in a significant gap in our national media studies. The responses collected here and the strategic positionings deployed by our respondents demonstrate that reception studies of this kind are well suited to offer us fresh insights into the ways that 'minority' viewers relate to, and engage with, cultural products that take up the burden of representing their lives within the host society. However, there is also much of interest here that goes beyond the work of representation and its subsequent reception by samples from target audiences. The responses collated in this article furnish some pertinent examples of how a discursive engagement with 'social' narratives necessarily engenders a set of strategic position-takings by which participants articulate their relationships with various social formations as well as different forms of the self. As such, incorporating an awareness of the broader operation of social imagination into our work has been rewarding in terms of illuminating the nuances of positiontaking that takes place in social studies.

Mills argued that the social imagination is what allows us to understand the relationship between our individual circumstances and large-scale social structures, and there is clear evidence here that our respondents were fully engaged in this process. By establishing a contextually located set of relationships between narrative protagonists, the self, intimates, strangers and broader social forces, each participant was able to offer a wideranging commentary on the sociology of migration and multiculturalism in New Zealand. Consequently, we are confident that reception studies continue to provide a useful means of 'putting people in the picture' and subsequently gaining insights into their empathic capabilities, and how this shapes their role as social agents. Since our study here is based on a very particular set of people, and the corresponding representations of their specific circumstances in New Zealand, we are also inclined to hypothesise about some central preoccupations that appear to shape a distinctively 'diasporic social imagination'. These responses, therefore, constitute a case study of social imagination at work in a multicultural context, underlining the utility of narrative media in providing a public forum for discussing cultural diversity. That is, since migrants have a common tendency to actively negotiate their positions in connection with the host society, we see common tropes emerging throughout the responses. These cumulative (rather than collective) articulations indicate a heightened consciousness of self, place and community, as well as the revealing some of the emotive interplay between being, becoming and belonging in their new situation. 
Our sample of 'diasporic films' thereby provided a ready reference point for our respondents as they navigated the social complexities of those narratives in relation to their own life stories. This imaginative process had both a self-referential aspect (that we might call identity formation) as well as an external, social aspect (that we might call social identification). As such, the articulation of these inner and outer worlds by respondents allowed us to analyse something of the complex relationships, ever-changing identities and culturally laden flows that shape contemporary diasporic social life. These self-expressions, therefore, reveal the underlying notions that shape the respondents' expectations and understandings of the society they live in. Thus, our primary interest in engaging the social imagination of diasporic communities in New Zealand was well served in practical terms, while a broader concept of diasporic subjectivity (as a confluence of impressions and effects anchoring migratory experiences) offered us some intriguing ways to think of social imagination as both a political imperative and an everyday project in a multicultural society.

\section{Funding}

This research received no specific grant from any funding agency in the public, commercial, or not-for-profit sectors.

\section{References}

Anderson B (1991) Imagined Communities: Reflections on the Origins and Spread of Nationalism. London: Verso.

Appadurai A (1996) Modernity at Large: Cultural Dimensions of Globalisation. Minneapolis: University of Minnesota Press.

Anthias F (1998) Evaluating diaspora: beyond ethnicity? Sociology 32(3): 557-580.

Athique A (2008) Media audiences, ethnographic practice and the notion of a cultural field. European Journal of Cultural Studies 11(1): 25-41.

Athique A (2011) Theorising the diasporic audience: the case of Indian films. Participations: Journal of Audience Research 8(2): 1-23.

Baumann M (2000) Diaspora: genealogy of semantics and transcultural comparison. Numen: International Review for the History of Religions 47(3): 313-337.

Clifford J (1994) Diasporas. Cultural Anthropology 9(3): 302-338.

Cunningham S (2001) Popular media as public 'sphericules' for diasporic communities. International Journal of Cultural Studies 4(2): 131-147.

Cunningham S and Sinclair J (eds) (2000) Floating Lives: The Media and Asian Diasporas. St Lucia: University of Queensland Press.

Giddens A and Sutton PW (2013) Sociology, 7th edn. Cambridge: Polity Press.

Gillespie M (1995) Television, Ethnicity and Cultural Change. London: Routledge.

Gitlin T (1998) Public sphere or public sphericules? In: Liebes T and Curran J (eds) Media, Ritual and Identity. London: Routledge, pp. 175-202.

Hall S (1990) Cultural identity and diaspora. In: Rutherford J (ed.) Identity: Community, Culture, Difference. London: Lawrence and Wishart, pp. 222-237.

Hall S (1993) Culture, community, nation. Cultural Studies 7(3): 349-363.

Hall S, Morley D and Chen K (1996) Stuart Hall: Critical Dialogues in Cultural Studies. London: Routledge. 
Higson A (2000) The limiting imagination of national cinema. In: Hjort M and Mackenzie S (eds) Cinema and Nation. London: Routledge, pp. 63-74.

Karim KH (ed.) (2003) The Media and Diaspora. London: Routledge.

Khorana S (ed.) (2013) Crossover Cinema: Cross-cultural Film from Production to Reception. London: Routledge.

Mills CW (1959) The Sociological Imagination. London: Oxford University Press.

Naficy H (2001) Accented Cinema: Exilic and Diasporic Filmmaking. Princeton, NJ: Princeton University Press.

Schlesinger P (2000) The sociological scope of national cinema. In: Hjort M and Mackenzie S (eds) Cinema and Nation. London: Routledge, pp. 19-31.

Smeith G and Dunstan K (2004) Ethnic population projections: issues and trends. In: Statistics New Zealand, Key Statistics, pp. 9-14. Available at: http://www.stats.govt.nz/browse_for stats/population/estimates_and_projections/ethnic-pop-projections-issues-and-trends.aspx (accessed 16 June 2012).

Ward C and Masgoret AM (2008) Attitudes toward immigrants, immigration, and multiculturalism in New Zealand. International Migration Review 42(1): 227-248.

Zalipour A (2013) 'New' New Zealand stories on the periphery of New Zealand cinema. Communication Journal of New Zealand: He Kohinga Korero 13(1): 6-23.

Zalipour A (forthcoming) Emerging Asian New Zealand filmmakers in New Zealand cinema. In: Goldsmith B, Ryan M and Lealand G (eds) Directory of World Cinema: Australia and New Zealand 2. Bristol: Intellect.

\section{Author biographies}

Arezou Zalipour is based in the Audience Research Unit and School of Arts, University of Waikato. Her research focuses primarily on the intersections of (visual) media/arts, diaspora/transnationalism, society, and culture, with a secondary research area in poetics. The former encompasses current work on the Asian diasporas in New Zealand film and visual arts/culture. The latter represents a long-standing interest in philosophy of imagination and creativity.

Adrian Athique is Chair of the School of Arts, University of Waikato. He is the author of The Multiplex in India: A Cultural Economy of Urban Leisure (Routledge, 2010, with Douglas Hill), Indian Media: Global Approaches (Polity, 2012), Digital Media and Society (Polity, 2013) and is currently completing Transnational Audiences: Media Reception on a Global Scale (Polity, 2015). 